\title{
Persepsi dan Perilaku Wanita Usia Subur dalam Melakukan Tes Inspeksi Visual Asam Asetat
}

\author{
Liyasda Amalis Sahr*), Tanjung Anitasari Indah Kusumaningrum*) \\ *) Program Studi Kesehatan Masyarakat Universitas Muhammadiyah Surakarta \\ Korespondensi: tanjung.anitasari@ums.ac.id
}

\begin{abstract}
Background: Sukoharjo Regency is ranked as the four highest positive IVA in Central Java with $19.35 \%$ of fertile women have IVA tes positive. This percentage has exceeded the target set by Ministry of health as many as 3\%. The lowest of IVA test visits in this Regency was in sukoharjo subdistric which only 47 fertile women $(0,19 \%)$ has been tested. This research aims to exlplore the perceptions of fertile women in terms of IVA test based on health belief model theory.

Method: The research employs qualitative method with case study approach. In-depth interviews were conducted to 14 fertility women and their husbands. One midwife also has been interviewed who was provider of IVA test in Sukoharjo Community Health Centers as an informant triangulation

Results: The results showed that the majority of fertile women has not been tested. The incomprehensive information about IVA test exposure is as the cause of the women didn't want to do the test. Lack of knowledge about the process of IVA test, feel fear and shame including feeling against to religion principles as the inhibitor factors to do test. Beside the need complete socialization from health provider and husband's support and friend make women easier want to do a IVA test. This study recommends providing complete information to fertile women and their husbands' by health provider as the key factor to improve the IVA test among fertile women.
\end{abstract}

Keywords: Servical Cancer, women fertile age, visual inspection with acetic acid (IVA)

\begin{abstract}
ABSTRAK
Latar Belakang: Kabupaten Sukoharjo menempati sebagai salah satu kabupaten tertinggi positif IVA di Jawa Tengah dengan presentase sebesar 19.35\%. Jumlah tersebut melampaui ambang batas yang ditetapkan oleh Kementerian Kesehatan RI yaitu sebesar 3\%. Kunjungan tes IVA terendah terdapat di Puskesmas Kecamatan Sukoharjo yaitu hanya $47(0,19 \%)$ wanita usia subur (WUS) yang telah tes IVA. Penelitian ini bertujuan untuk memahami perilaku WUS yang telah bersedia dan tidak bersedia melakukan tes IVA berdasarkan teori Health Belief Model.

Metode: Jenis penelitian ini merupakan penelitian kualitatif dengan pendekatan studi kasus WUS yang bersedia dan tidak bersedia melakukan tes. Sebanyak 14 WUS terlibat dalam penelitian ini dan disertai dengan 14 suami WUS yang bersedia dilakukan wawancara mendalam sebagai teknik pengumpulan data. Satu orang bidan sebagai pelaksana program IVA tes juga di wawancara mendalam sebagai informan triangulasi.

Hasil: Hasil penelitian menunjukkan bahwa sebagian besar WUS belum melakukan tes IVA. Persepsi hambatan yang dirasakan oleh WUS merupakan persepsi yang paling melatarbelakangi WUS tidak melakukan tes IVA. Alasan WUS enggan melakukan tes IVA karena kurangnya informasi tentang tes IVA sehingga WUS merasa tidak faham tentang IVA, selain kesibukan, perasaan takut, dan malu. Persepsi yang paling berkaitan dengan WUS melakukan tes IVA adalah cues to action. Alasan WUS melakukan tes IVA adalah karena
\end{abstract}


mendapat sosialisasi lengkap sehingga faham manfaatnya, selain juga dukungan dari suami serta adanya contoh dari teman yang telah melakukan tes IVA.

Kata Kunci: Kanker Serviks, Wanita Usia Subur, IVA, persepsi, Health Belief Model

\section{PENDAHULUAN}

Penyakit kanker serviks atau kanker leher rahim merupakan masalah kesehatan yang penting untuk menjadi perhatian wanita di seluruh dunia. Pada tahun 2012, kanker serviks dengan jumlah kasus $527.624(7,9 \%)$ adalah jenis kanker yang menduduki peringkat keempat paling umum ditemukan pada wanita di dunia. ${ }^{(1)}$

Angka kematian kanker serviks sebanyak 265.672 orang $(7,5 \%)$, dimana $70 \%$ kasus berasal dari Negara berkembang. Angka kematian akibat kanker serviks di Indonesia sebesar 9.498 orang $(10,3 \%) .{ }^{(1)}$ Tingginya angka kematian pasien kanker serviks dikarenakan keterlambatan diagnosis dan pengobatan. Pasien kanker serviks pada umumnya baru mengetahui kondisinya ketika sudah memasuki stadium lanjut dimana sel kanker telah menyebar ke organ lain di dalam tubuh. Inilah penyebab pengobatan yang dilakukan menjadi semakin sulit. ${ }^{(2)}$

Mengingat tingginya prevalensi kanker serviks pada wanita di Indonesia maka perlu dilakukan tindakan pencegahan dan deteksi dini yang dilakukan oleh penyedia pelayanan kesehatan. Tindakan pencegahan kanker serviks dapat dilakukan mengingat sel kanker serviks yang dapat diketahui pada stadium awal yaitu sel abnormal yang ditemukan pada permukaan serviks dapat diobati dengan tingkat kesembuhan hampir $100 \% .^{(3)}$

Metode screening kanker serviks dengan pemeriksaan Inspeksi Visual Asam Asetat (IVA) merupakan salah satu metode deteksi dini kanker serviks yang memungkinkan untuk tersedia pada pelayanan kesehatan primer karena praktis, murah, serta tingkat sensitifitas tinggi yaitu dengan sensitifitas pemeriksaan rata - rata sebesar $77 \%$ (range antara 56-94\%) dan spesifisitas rata-rata 86\% (antara 74-94\%) signifikan. Screening kanker serviks dengan frekuensi 5 tahun sekali dapat menurunkan kasus kanker leher rahim sampai $83,6 \%$. $^{(4)}$

Jumlah WUS yang melakukan pemeriksaan IVA di Jawa tengah tahun 2016 sebanyak 56.337 WUS atau 1,27\%. Jumlah tersebut masih belum mencapai target yang telah ditetapkan yaitu sebesar 10\%. Jumlah WUS di Jawa Tengah yang melakukan tes IVA diketahui bahwa sebanyak $3.946(7,01 \%)$ WUS memiliki hasil pemeriksaan IVA positif. Jumlah tersebut cukup tinggi melampaui ambang batas yang ditetapkan oleh Kementerian Kesehatan yaitu 3\%. Kabupaten Sukoharjo menempati empat tertinggi positif IVA 
yaitu Grobogan 27,27\%, Temanggung $23,71 \%$, Tegal 22,48\%, dan Sukoharjo sebesar $19.35 \%{ }^{(5)}$

Sesuai data rekapitulasi kunjungan tes IVA Kabupaten Sukoharjo tahun 2016, dari 10 puskesmas yang menyediakan pemeriksaan IVA diketahui bahwa Puskesmas Kecamatan Sukoharjo memiliki kunjungan IVA terendah yaitu sejumlah 47 WUS $(0,19 \%)$. Jumlah tersebut masih belum mencapai target yang telah ditetapkan oleh Dinas Kesehatan Kabupaten Sukoharjo yaitu sebesar 10\%.(6)

Perilaku WUS dalam melakukan pencegahan penyakit kanker serviks dengan deteksi dini masih rendah. Perilaku tersebut dipengaruhi oleh faktor persepsi dan keyakinan WUS terhadap kanker serviks yang rendah. ${ }^{(7)}$ Hal ini sesuai dengan teori HBM yang dikemukakan oleh Rosenstock pada tahun 1974. Individu akan mengambil keputusan terhadap suatu penyakit untuk melindungi dirinya dengan cara memandang kerentanan (perceived susceptibility), keseriusan/keparahan (perceived severity), manfaat (perceived benefits), hambatan (perceived barriers), isyarat untuk bertindak (cues to action), kemampuan diri (self-efficacy) dalam melakukan tindakan kesehatan. ${ }^{(8)}$

Berdasarkan penelitian terdahulu menunjukkan hasil bahwa terdapat pengaruh persepsi kerentanan, keparahan, ancaman, manfaat, hambatan dan isyarat untuk bertindak WUS untuk melakukan tes IVA. Pada penelitian tersebut peneliti dijelaskan bahwa lebih dari separuh WUS tidak bersedia melakukan tes IVA tanpa diketahui alasannya. Sehingga perlu dilakukan secara mendalam sebagai penyebab banyaknya WUS yang tidak bersedia melakukan tes IVA maupun yang bersedia. Pengetahuan WUS tentang IVA, persepsi dan sikap WUS perlu diteliti secara mendalam melalui penelitian kualitatif sehingga diketahui secara mendetail faktor penghambat dan pendukung WUS dalam melakukan tes IVA. $^{(9)}$

Tingginya angka IVA positif di Kabupaten Sukoharjo, masih rendahnya perilaku WUS untuk melakukan pemeriksaan IVA, dan belum diketahuinya alasan WUS untuk melakukan dan tidak melakukan IVA di Puskesmas Sukoharjo maka peneliti tertarik untuk melakukan penelitian dengan tujuan mengeksplorasi secara mendalam faktor penghambat dan pendukung Wanita Usia Subur (WUS) dalam melakukan pemeriksaan tes IVA berdasarkan teori Health Belief Model.

\section{METODE}

Jenis penelitian ini merupakan penelitian kualitatif dengan menggunakan pendekatan studi kasus tentang kesediaan WUS dalam melakukan tes IVA di Puskesmas Kecamatan Sukoharjo. Pada 
penelitian studi kasus peneliti menyelidiki secara cermat suatu program, peristiwa, aktivitas, proses atau sekelompok individu. ${ }^{(10)}$ Penentuan informan menggunakan cara purposive sample yaitu WUS yang berdomisili di wilayah kerja Puskesmas Sukoharjo, menikah, dan pernah mengunjungi klinik KIA Puskesmas Sukoharjo. Penelitian ini dilakukan pada bulan januari tahun 2018 dengan menggunakan metode wawancara mendalam terhadap 14 informan utama yaitu WUS dan 14 orang suaminya serta satu orang bidan sebagai petugas tes IVA yang dijadikan sebagai informan triangulasi. Inform consent diberikan kepada WUS dan suaminya dan ditandatangani sebagai kesediaan menjadi informan.

\section{HASIL DAN PEMBAHASAN}

Informan utama pada penelitian ini adalah 14 WUS dengan range usia antara 21-43 tahun. Kebanyakan WUS ber pendidikan WUS SMP/sederajat (6 orang) dan SMA/ sederajat (6 orang) dan hanya satu orang lulusan SD dan satu orang lulusan sarjana. Adapun karakteristik suami juga demikian hampir sama dengan WUS, kebanyakan lulusan SMA sebanyak 7 orang, sebagian kecil lulusan SD dan SMP sebanyak 4 orang dan sangat sedikit yang lulusan perguruan tinggi hanya 3 orang. Adapun latar belakang pekerjaan sebagian besar ibu rumah tangga ( 9 orang) dan sisanya pegawai swasta (7 orang) dan pegawai negeri. Pekerjaan suami sebagian besar adalah pegawai swasta (6 orang), wirausaha sebanyak 2 orang, sebagai buruh sebanyak 4 orang dan hanya sebagian kecil yang pegawai negeri (2 orang). Umur ratarata suami adalah antara 22-52 tahun.

Informan triangulasi 1 bidan yang merupakan provider dan pelaksana tes IVA di Puskesmas Kecamatan Sukoharjo dengan rentang 35 tahun dengan tingkat pendidikan D4 kebidanan.

\section{Perilaku WUS Melakukan Tes IVA}

Hasil Penelitian menunjukkan sebagian besar tidak bersedia melakukan tes IVA dan hanya sedikit yaitu 3 orang yang bersedia dan telah melakukan tes. Adapun faktor persepsi yang paling mendasari WUS tidak bersedia melakukan tes IVA berdasarkan teori Health Belief Model adalah persepsi hambatan (Perceived Barrier). Persepsi hambatan WUS dalam melakukan tes IVA terjadi karena kurangnya informasi yang didapat oleh WUS baik tentang manfaat, kerugian, proses tes IVA dan dampak bila tidak tes. Lebih banyak persepsi negative yang ada dalam pikiran WUS dalam melakukan tes IVA, seperti rasa sakit, bila terdeteksi sakit akan menjadi bahan pikiran yang membebani, rasa malu karena dilakukan didaerah sensitive serta ketakutan akan 
berlawanan dengan prinsip agama. Selain itu, kesibukan WUS dalam bekerja atau mengurus anak dan rumah tangganya membuat penghalang untuk melakukan tes menjadi bertambah. Hal ini seperti yang diungkapkan oleh WUS sebagai berikut:

"Saya masih belum berani melakukan tes, karena takut dan malu, saya juga tidak faham tentang tes IVA itu seperti apa masih banyak teman yang tidak tes juga." ( Ibu A)

Semakin besar faktor penghambat yang dirasakan maka semakin sulit untuk melakukan tes. Hambatan yang dirasakan merupakan suatu konsekuensi negatif yang potensial untuk menurunkan keinginan yang timbul ketika mengambil tindakan tertentu sesuai dengan teori HBM yang dikembangkan oleh Glanz, Rimer dan Viswanath. ${ }^{(9,11)}$

Berdasarkan hasil penelitian hanya terdapat 3 orang WUS yang telah melakukan tes IVA. Ketiga WUS tersebut memiliki alasan yang berbeda sebagai pendorong dalam melakukan tes IVA. Salah satu WUS melakukan tes IVA karena diwajibkan untuk mengikuti tes IVA karena profesinya sebagai ketua PKK sehingga harus memberi contoh kepada warganya, dan selain itu juga karena menjadi istri dari pegawai kelurahan. Sebagai ketua PKK dianggap penting untuk memberikan contoh kepada orang lain dan masyarakatnya, sehingga WUS tersebut harus memiliki self efficacy atau kepercayaan diri yang kuat untuk mampu melakukan tes IVA. Selain alasan diwajibkan oleh istansi kelurahan, WUS melakukan tes IVA, WUS tersebut juga ingin mengetahui kondisi kesehatannya walaupun ini tidak menjadi alasan utama. Seperti yang diungkapkannya sebagai berikut:

"Sebagai ketua PKK saya harus memberikan contoh dan teladan kepada ibu-ibu disini, walaupun saya juga takut, tapi karena saya mengajak ibu-ibu maka saya harus lebih dulu melakukan tes agar ibu-ibu lain tidak takut." (Ibu B)

Berbeda dengan WUS tesebut, terdapat seorang WUS yang melakukan tes IVA atas dasar kesadarannya bahwa deteksi dini kanker serviks penting untuk wanita. Kesadaran untuk melakukan tes IVA tersebut muncul setelah mengikuti penyuluhan di pertemuan RT. Alasan WUS tersebut ditinjau dari teori Health Belief Model adalah merupakan pengaruh faktor persepsi cues to action external yaitu berupa informasi dari luar yang didapat. Faktor eksternal ini menumbuhkan keyakinan dan sikap pada WUS tersebut untuk melakukan tes IVA.

Kebanyakan WUS yang sudah melakukan tes IVA mendapat dukungan penuh dari masing-masing suaminya. Dukungan suami ini sangat mempengaruhi 
atau memperkuat keyakinan untuk melakukan tes IVA. Bentuk dukungan suami tersebut dapat berupa memotivasi WUS dengan menyuruh, mengantar dan mengingatkan akan pentingnya tes. Memberi dukungan dan nasehat terkait keuntungan yang bisa didapatkan istri apabila melakukan tes IVA, mengantarkan istri melakukan tes IVA, mendampingi dan mendukung istri dalam menerima hasil, serta mendampingi istri apabila memerlukan penanganan lanjut merupakan faktor penting yang memperkuat istri mau dan bersedia tes IVA.

Pada saat melakukan tes IVA WUS merasakan cemas ketika melalui proses pemeriksaan karena belum mengetahui proses tes IVA dan takut apabila hasil tes IVA adalah positif. Upaya yang dilakukan WUS untuk mengatasi rasa cemas dan takut dalam melakukan tes IVA yaitu dengan bersama-sama teman dalam tes IVA agar lebih tenang dalam melakukan tes IVA. Perasaan tenang tersebut muncul karena apabila melakukan tes IVA bersama teman maka dapat saling berbincang dan saling menenangkan sehingga menghilangkan kecemasan.

Kebanyakan WUS melakukan tes IVA di Puskesmas Begajah yang merupakan Puskesmas pembantu di Puskesmas Kecamatan Sukoharjo. Puskesmas Kecamatan Sukoharjo memiliki 6 puskesmas pembantu dan yang memiliki layanan tes IVA hanya di puskesmas induk dan Puskesmas Begajah. Kebanyakan WUS yang telah melakukan tes IVA menjelaskan bahwa prosedur atau tahapan dalam melakukan tes IVA yaitu dimulai dari pendaftaran, persiapan untuk pemeriksaan, selanjutnya dilakukan pemeriksaan payudara terlebih dahulu dan tes IVA, setelah selesai pemeriksaan maka dilakukan konsultasi. Pada pemeriksaan tes IVA juga dilakukan pemeriksaan payudara karena memang sesuai pernyataan yang diberikan petugas pelaksana IVA di Puskesmas Kecamatan Sukoharjo, bahwa program layanan IVA merupakan satu rangkaian dengan SADANIS (Periksa Payudara Klinis) karena program yang ada diharapkan dapat dilakukan deteksi dini kanker serviks dan payudara pada WUS.

\section{Persepsi Kerentanan (Perceived Susceptibility) WUS Melakukan Tes IVA} Sebagian besar WUS dalam penelitian ini memiliki pengetahuan tentang kanker serviks dan tes IVA yang kurang. WUS mengaku tidak mengetahui secara pasti seperti apa penyakit kanker serviks. Mereka hanya mengetahui dan mendengar sebatas nama penyakitnya dan beranggapan bahwa terdapat kanker pada organ kewanitaan. Terdapat beberapa WUS yang juga tidak mengetahui gejala dari kanker serviks. Hanya terdapat empat WUS yang telah mendapat informasi 
tentang kanker serviks melalui penyuluhan yang diberikan oleh petugas puskesmas. Diantara empat WUS tiga orang diantaranya sudah melakukan tes IVA. Dari beberapa penelitian terdapat hubungan antara tingkat pengetahuan WUS dengan kesediaan tes IVA. ${ }^{(12)}$ Rendahnya pengetahuan perempuan mengenai kanker serviks mengakibatkan rendahnya keinginan perempuan untuk melakukan deteksi dini. ${ }^{(4)}$ Namun hasil penelitian ini juga menunjukkan bahwa sebagian besar WUS (10 orang) merasa bahwa dirinya tidak rentan terhadap kanker serviks dikarenakan menurut mereka tidak pernah melakukan perilaku yang berisiko sehingga memicu terjadinya kanker serviks. Perilaku yang berisiko tersebut antara lain mereka tidak pernah bergantiganti pasangan, dan telah menjaga kebersihan organ kewanitaannya dengan baik. Keyakinan tidak merasa rentan tersebut dapat menjadi salah satu faktor WUS tidak bersedia melakukan tes IVA.

"Saya tidak pernah neko-neko mbak, tidak pernah melakukan dengan orang lain kecuali dengan suami saya saja." (Ibu C)

Berdasarkan hasil penelitian terdapat empat orang WUS yang merasa rentan terkena kanker serviks karena WUS merupakan wanita dewasa yang telah melakukan hubungan seksual secara aktif dan pola hidup yang tidak sehat seperti memakan makanan yang tidak sehat seperti makanan instan dan berpengawet. Menurut pernyataan keempat WUS tersebut, hanya ada seorang WUS yang kemudian melakukan deteksi dini dengan tes IVA. Artinya walaupun informan sudah merasa rentan belum tentu mau melakukan tes, sehingga ada penyebab lain yang dapat mendukung kemauan WUS untuk tes.

Menurut teori HBM Individu yang memiliki persepsi kerentanan yang tinggi terhadap kanker serviks seharusnya individu tersebut akan melakukan usaha pencegahan kanker serviks salah satunya yaitu dengan melakukan tes IVA. Pernyataan tersebut berbeda dengan hasil penelitian ini yang menunjukkan hanya ada seorang WUS yang mau melakukan IVA karena dirinya merasa rentan karena WUS meyakini bahwa wanita yang telah aktif berhubungan seksual berisiko terkena kanker serviks. WUS yang merasa rentan terkena kanker serviks tidak melakukan tes IVA kemungkinan karena mereka tidak faham salah satu tindakan pencegahan kanker serviks adalah melalui deteksi dini kanker serviks. ${ }^{(9)}$

\section{Persepsi Keparahan / Keseriusan (Perceived Severity) WUS Melakukan} Tes IVA

Menurut hasil penelitian, seluruh WUS beranggapan bahwa kanker serviks 
merupakan penyakit yang memiliki dampak sangat serius. Dampak yang serius ini karena mereka meyakini bahwa penderita kanker serviks sama dengan divonis mati, pengobatannya sangat sulit dan membutuhkan waktu lama, serta biaya pengobatan yang mahal. Terdapat pengaruh persepsi keparahan penyakit atau gejala yang dirasa dengan kemauan melakukan tes IVA. Hasil penelitian tersebut berbeda dengan penelitian ini, karena dari hasil penelitian ini diketahui bahwa dari total 14 WUS yang memiliki keyakinan bahwa kanker serviks itu merupakan penyakit yang serius hanya ada 3 orang WUS yang kemudian melakukan tes IVA. Tiga WUS tersebut melakukan tes IVA karena mendapatkan informasi pencegahan kanker serviks dengan metode IVA dari penyuluhan dan dukungan informasi dari suaminya. ${ }^{(9)}$

Terdapat delapan WUS yang tidak merasa akan sakit kanker serviks apabila tidak melakukan tes IVA. Keyakinan tersebut muncul karena WUS tidak merasakan gejala atau keluhan, sehingga WUS percaya tidak akan sakit kanker serviks walaupun tidak melakukan tes IVA. Kecuali apabila memang merasakan adanya gejala seperti keputihan tidak normal atau keluhan yang mengarah ke kanker serviks.

Menurut pernyataan dari bidan pelaksana program IVA di Puskesmas
Kecamatan Sukoharjo, penyakit kanker serviks memang belum menunjukkan gejala pada awal munculnya sel abnormal pada serviks. Gejala kanker serviks contohnya nyeri saat berhubungan seksual, keputihan berbau busuk disertai darah, pendarahan dan sebagainya akan muncul setelah sel abnormal tersebut tumbuh menjadi sel kanker pada serviks. Pernyataan tersebut sesuai dengan yang dialami oleh salah satu WUS yang telah melakukan tes IVA, walaupun WUS tidak pernah merasakan gejala atau keluhan namun setelah dilakukan tes IVA ternyata hasilnya positif dan kemudian harus menjalani cryo therapy.

\section{Persepsi Keuntungan (Perceived Benefits) WUS Melakukan Tes IVA}

Sebagian besar WUS berpendapat bahwa keuntungan melakukan tes IVA adalah agar dapat segera mengetahui kondisi kesehatan berpotensi kanker serviks atau tidak sehingga bisa segera mengambil tindakan lanjutan atau melakukan pencegahan. Pernyataan WUS tersebut sejalan dengan pernyataan informan triangulasi (provider tes IVA di Puskesmas Kecamatan Sukoharjo) menjelaskan bahwa apabila hasil tes IVA menunjukkan positif ini belum tentu itu didiagnosa kanker serviks karena butuh waktu dalam jangka 5 sampai 6 tahun sel yang tidak normal tersebut bisa berubah 
menjadi kanker serviks. Dilakukannya deteksi dini kanker serviks dengan metode tes IVA tujuannya agar dapat segera diketahui bila positif maka sel tidak normal pada mulut rahim agar tidak tumbuh menjadi sel kanker harus segera diobati. Deteksi kanker serviks secara dini perlu dilakukan karena sebenarnya perkembangan kanker serviks memerlukan waktu lama. Dari prevasif ke invasive memerlukan waktu kurang lebih 10 tahun atau lebih. Screening kanker serviks dengan frekuensi 5 tahun sekali dapat menurunkan kasus kanker leher rahim sampai $83,6 \%$.

Walaupun tes IVA penting namun masih terdapat suami yang berpendapat bahwa tes IVA tidak bermanfaat. Sesuai hasil penelitian terdapat dua suami informan yang merupakan suami dari WUS yang berpendapat bahwa melakukan tes IVA tidak bermanfaat karena apabila istri memang tidak mengalami gejala maka tidak perlu dilakukan tes karena akan hanya menambah beban pikiran. Informan menganggap melakukan pengecekan kesehatan rutin itu tidak penting karena akan menambah pikiran apabila mengetahui hasil yang buruk tentang kesehatannya. Mereka juga memiliki anggapan kebanyakan dokter dan petugas hanya akan menakut-nakuti pasien apabila melakukan pemeriksaan.
"Menurut saya kalo istri saya tidak punya gejala atau tanda, tidak perlu di tes segala...nanti malah menambah beban pikiran saja." (SI, 35 tahun)

Menurut informasi dari petugas pelaksana program IVA di Puskesmas Kecamatan Sukoharjo, belum ada penyuluhan kepada suami terkait sosialisasi program IVA. Suami dari WUS juga perlu mendapatkan informasi terkait kanker serviks dan tes IVA, karena apabila suami memiliki salah persepsi terkait tes IVA maka suami kurang mendukung dan menjadi penghambat untuk WUS melakukan tes IVA. Hendaknya pihak puskesmas juga melakukan sosialisasi kepada bapak-bapak (suami WUS), sosialisasi bisa dilakukan ketika perkumpulan rutin bapak-bapak seperti arisan, pengajian atau saat melakukan Survey Mawas Diri (SMD) dan Musyawarah Masyarakat Desa (MMD).

\section{Persepsi Hambatan (Perceived Barriers) WUS Melakukan Tes IVA}

Seluruh WUS dalam penelitian ini memiliki pendapat yang baik tentang tes IVA sebagai deteksi dini kanker serviks. Pendapat baik WUS terhadap tes IVA sebagai deteksi dini kanker serviks tidak menjamin dan sejalan dengan perilaku mereka untuk tes. Dari total informan sebanyak 14 WUS terdapat 11 WUS yang belum melakukan tes IVA. Alasan WUS 
belum melakukan tes IVA adalah karena adanya hambatan-hambatan antara lain:

1. Kurangnya pengetahuan manfaat tes

Kurangnya informasi yang didapat menyebabkan kurangnya pemahaman tentang manfaat dari tes IVA. Kurangnya petugas pemeriksa dan kurangnya ketersediaan alat, serta akses menuju pelayanan kesehatan oleh WUS, dan maupun tenaga kesehatan yang kurang trampil menjadi penghambat pelaksanaan IVA tes. ${ }^{(9)}$

Selain itu faktor kesulitan dalam mengatur waktu untuk melakukan pemeriksaan kesehatan termasuk tes IVA oleh WUS karena harus bekerja atau menjaga dan mengurus rumah tangga juga menambah sulitnya keberhasilan pelaksanaan kegiatan tes dilakukan oleh puskesmas.

\section{Adanya rasa takut}

Perasaan takut yang dirasakan oleh WUS adalah karena kurang fahamnya informan tentang proses pemeriksaan IVA selain juga rasa takut untuk mengetahui hasilnya terutama bila hasilnya positif dan akan berdampak buruk terhadap kesehatannya.

\section{Adanya rasa malu}

Informan mengaku merasa malu dalam melakukan tes IVA. Rasa malu tersebut karena harus dibuka organ kewanitaannya dan diperiksa oleh orang lain. Rasa malu tersebut akan semakin bertambah apabila tenaga medis yang melakukan pemeriksaan adalah seorang laki-laki. Ditambah lagi dengan kepercayaan informan yang bertentangan dengan prinsip agama bila aurat dilihat oleh orang lain.

4. Kurangnya sosialisasi akan manfaat tes IVA

Hampir seluruh WUS mengaku belum mengetahui tes IVA sebelumnya. Dari ketidaktahuan tersebut sehingga sangat wajar apabila informan tidak melakukan tes IVA karena minimnya pengetahuan tentang manfaat, tahapan dan gambaran proses tes, dan dampak dari hasil tes. Informan mengaku informasi tersebut masih sangat minim didapat. Persepsi hambatan dalam tes IVA membuat informan atau WUS enggan melakukan tes tersebut.

\section{Kemampuan Diri (Self-efficacy)}

Berdasarkan hasil penelitian terdapat 10 WUS yang mengaku mampu untuk melakukan tes IVA. Namun pernyataan tersebut tidak sesuai dengan tindakan WUS yaitu dari total informan utama 14 WUS hanya ada 3 WUS yang telah melakukan tes IVA. Mereka beranggapan bahwa walaupun sebenarnya WUS merasa mampu untuk melakukan, namun hambatan-hambatan berupa kesibukan, rasa takut terhadap proses, takut mengetahui hasil yang buruk, dan 
tidak mendapat informasi terkait tes IVA secara lengkap membuat WUS bersikap enggan untuk periksa. WUS yang memiliki self efficacy yang kuat tetapi tidak melakukan upaya pencegahan melalui deteksi dini kanker serviks dengan tes IVA ataupun papsmear karena kurangnya pemahaman metode tersebut sebagai bagian upaya pencegahan. ${ }^{(13)}$ Health Belief Model menjelaskan bahwa seseorang umumnya tidak melakukan sesuatu yang baru kecuali seseorang berpikir dapat melakukannya. Jika seseorang percaya suatu perilaku baru yang berguna (banyaknya manfaat yang dirasa), tetapi berpikir dia tidak mampu melakukan itu (merupakan penghalang dirasakan), kemungkinan bahwa hal tersebut tidak akan dilakukan. ${ }^{(8)}$

Teori tersebut sesuai dengan pengalaman yang dialami oleh salah satu WUS yaitu IU 3 yang telah melakukan tes IVA. Informan merupakan WUS yang berprofesi sebagai ketua PKK, sehingga diwajibkan untuk mengikuti tes IVA. WUS merasa yakin mampu melakukan tes IVA karena informan harus menjadi contoh warganya karena profesinya sebagai ketua PKK. Tanpa adanya keyakinan pasti WUS tidak akan melakukan tes IVA tersebut, walaupun itu diwajibkan sekalipun. Informan yang jabatannya sebagai ketua PKK berperan menyampaikan informasi kepada warganya terkait informasi tentang kanker serviks dan tes IVA yang didapatkan dari penyuluhan di Kecamatan Sukoharjo yang dilakukan oleh Puskesmas Kecamatan Sukoharjo.

Tidak hanya menyampaikan namun WUS yang berprofesi sebagi ketua PKK wajib mengajak warganya dalam melakukan tes IVA. WUS mengaku bahwa telah berhasil mengajak warganya melakukan tes IVA setelah memberikan contoh dan menceritakan pengalamannya dalam melakukan tes. Namun menurut informasi dari IU 3 masih banyak warga yang sulit untuk diajak untuk melakukan tes IVA karena beralasan takut, tidak ada waktu atau malu.

\section{Isyarat Bertindak (Cues to Action) WUS Melakukan Tes IVA}

1. Faktor Internal

Menurut hasil penelitian 13 WUS mengaku bahwa tidak ada keluarga yang memiliki riwayat kanker serviks. Namun terdapat seorang WUS yang mengaku memiliki kerabat jauh yang menderita kanker serviks, menjalani kemoterapy dan akhirnya meninggal dunia. Walaupun WUS mengaku merasa takut apabila sampai sakit kanker serviks seperti kerabatnya tersebut namun WUS tetap tidak melakukan tes IVA karena memiliki trauma medis.

Terdapat 2 orang WUS yang mengaku memiliki penyakit kelanjar getah 
bening, salah satu WUS telah melakukan tes IVA dan seorang WUS lagi tidak melakukan tes IVA karena tidak mengetahui metode pencegahan dengan tes IVA. Adanya kerabat yang mengalami penyakit tersebut membuat WUS menjadi lebih berhati-hati dan melakukan langkah pencegahan dengan lebih menjaga pola makan karena takut mengalami penyakit serupa.

\section{Faktor eksternal}

Sebagian besar WUS mengaku belum pernah mendapatkan sosialisasi terkait kanker serviks dan tes IVA. Pernyataan tersebut sejalan dengan pernyataan informan triangulasi yang merupakan provider tes IVA di Puskesmas Sukoharjo yang menjelaskan bahwa penyuluhan dari puskesmas baru tersentral di Kecamatan dengan dihadiri perwakilan ibu lurah tiap desa dan kader kesehatan dengan harapan akan disampaikan pada lini terbawah. Namun pada pelaksanaannya puskesmas belum bisa mengawal sampai lini terbawah.

Menurut penjelasan informan triangulasi yang merupakan provider tes IVA di Puskesmas Sukoharjo, pihak puskesmas belum bisa melakukan pengawasan sampai lini terbawah dan memaksimalkan penyuluhan karena keterbatasan sumberdaya manusia yang memegang program IVA ini dan keterbatasan dana untuk sosialisasi.
Program IVA juga belum menggandeng bagian promosi kesehatan Puskesmas untuk melakukan promosi kesehatan karena belum bisa menyingkronkan agenda dengan bagian promosi kesehatan Puskesmas.

"Iya setahu saya memang baru sampai kecamatan dilakukan penyuluhan tentang tes IVA sekaligus juga dengan SADANIS (pemeriksaan payu dara klinis) karena keterbatasana dana dan juga sumber daya sehingga belum sampai ke desa-desa." (Bidan Puskesmas)

Terdapat 2 informan yang mengaku pernah mengikuti penyuluhan di pertemuan RT dan PKK. Informan yang mengikuti penyuluhan di pertemuan RT mengaku bahwa narasumbernya yaitu mirip dengan perawat, namun ternyata penjual obat. Kemudian untuk informan yang mengikuti penyuluhan di pertemuan PKK narasumber dari bidan Desa yang menjelaskan tentang kanker serviks dan tes IVA. Metode yang digunakan menurut kedua informan adalah dengan metode ceramah. Penyuluhan tersebut dirasa masih belum meyakinkan ibu-ibu untuk melakukan tes IVA di puskesmas.

Terdapat seorang WUS yang mengaku sering mengikuti pertemuan atau penyuluhan kesehatan di kecamatan karena memang informan menjabat sebagai ketua 
penggerak PKK dan suaminya sebagai Lurah di desa tersebut. Sehingga informan sudah sering terpapar informasi tersebut dengan mengikuti penyuluhan dan mengaku menjadi penggerak penyuluhan yang mengajak warganya untuk tes IVA. Mengikuti sosialisasi tentang tes IVA dan kanker serviks di kecamatan yang narasumbernya dari puskesmas Sukoharjo melalui ceramah dengan alat bantu proyektor dan pemberian leaflet membuat informan banyak mendapat informasi tentang hal tersebut.

Pernyataan tersebut sejalan dengan pernyataan informan triangulasi (provider IVA Puskesmas Sukoharjo), bahwa puskesmas memiliki program sosialisasi tes IVA dan kanker serviks baru sampai di tingkat kecamatan membuat belum seluruh WUS mendapat informasi tersebut. Metode penyampaiannya dengan cara ceramah dan menggunakan media LCD serta leaflet yang diberikan khusunya untuk para kader agar dapat menyampaikan kepada ibu-ibu diwilayahnya. Namun setelah melakukan sosialisasi fasilitator tidak melakukan evaluasi pre-test dan post-test, sehingga dari pihak puskesmas tidak mengetahui apakah pengetahuan dan perilaku WUS meningkat. Evaluasi yang dilakukan hanya dengan cara melihat angka cakupan yang meningkat. Pihak puskesmas berpatokan apabila angka cakupan meningkat berarti sosialisasi telah berhasil.

Menurut WUS yang telah mengikuti sosialisasi kanker serviks dan tes IVA, WUS menjadi berminat untuk melakukan tes IVA. Setelah mengikuti sosialisasi sehingga menjadi lebih sadar akan pentingnya deteksi dini kanker serviks dan keuntungan yang didapat apabila melakukan tes IVA.

Peneliti menyimpulkan bahwa adanya isyarat bertindak eksternal atau cues to action dalam metode tes IVA membuat individu atau WUS lebih mudah terdorong dalam melakukan tes IVA. Selain itu dukungan suami dan teman juga menjadi faktor penentu. Hal ini dikarenakan informasi melalui teman, petugas kesehatan, penyuluhan, media cetak dan elektronik dapat memengaruhi perilaku. Sehingga Puskesmas Kecamatan Sukoharjo sudah seharusnya menguatkan promosi kesehatan pada masyarakat khususnya tentang kanker serviks dan tes IVA kepada seluruh WUS dan suaminya.

\section{SIMPULAN}

Perilaku WUS dalam melakukan tes IVA dari total 14 WUS sebagai informan hanya 3 WUS yang telah melakukan tes IVA. Pengetahuan yang cukup, niat yang kuat dan tingginya dukungan suami memiliki peran penting untuk WUS dalam melakukan tes IVA. 
Persepsi kerentanan, yaitu merasa dirinya tidak rentan terhadap kanker serviks dikarenakan tidak melakukan perilaku yang berisiko memicu kanker serviks seperti berganti-ganti pasangan, keyakinan informan telah menjaga kebersihan organ kewanitaan merupakan penghambat informan melakukan tes.

Walaupun informan mempunyai persepsi keseriusan yang tinggi, dengan meyakini dampak kanker serviks yang sangat serius karena beranggapan penderita kanker serviks sama dengan divonis mati, pengobatannya sulit dan juga membutuhkan waktu lama, serta biaya pengobatan yang mahal, tetapi bagi WUS yang tidak merasa mempunyai gejala dan keluhan resiko sakit kanker serviks tetap enggan melakukan tes IVA.

Persepsi keuntungan/manfaat, keuntungan melakukan tes IVA menurut kebanyakan WUS adalah agar dapat segera mengetahui kondisi kesehatannya berpotensi kanker serviks atau tidak sehingga dapat segera diambil tindakan lanjutan atau melakukan tindakan pencegahan.

Persepsi hambatan yang dirasakan WUS kebanyakan adalah perasaan takut, malu, takut berlawanan dengan prinsip agama dan faktor kesibukan bekerja dan mengurus rumah tangga serta kurangnya dukungan suami merupakan faktor yang melemahkan terjadinya perilaku tes IVA.
Kebanyakan WUS merasa dirinya mampu melakukan tes IVA, namun mereka tetap enggan melakukan tes IVA karena lebih banyak faktor hambatan yang dirasa. Tiga orang WUS yang merasa mampu tetapi karena tidak merasa ada keluhan dan gejala beresiko maka akhirnya juga merasa tidak memerlukan tes IVA.

Kebanyakan WUS tidak merasa mengalami gejala terkena kanker serviks dan kebanyakan mereka juga belum pernah mendapatkan sosialisasi tes IVA dan suami juga tidak faham dan tidak mendukung tes, demikian juga masih banyak teman disekelilingnya belum melakukan tes IVA.

\section{KEPUSTAKAAN}

1. World Health Organization. Globocan 2012: Estimated Cancer Indance, Mortality and Prevalence Worldwide in 2012 [Internet]. International Agency for Research on Cancer (IARC); 2012. Available from: http://globocan.iarc.fr/Pages/fact_sheet s_population.aspx.

2. World Health Organization. Comprehensive Cervical Cencer Control : A Guide to Essential Practice. Geneva: Swizerland; 2014.

3. Rahayu D. Asuhan Ibu Dengan Kanker Serviks. Jakarta: Salemba Medika; 2015. 
4. Nuranna L. Skrining Kanker Servik dengan Metode IVA. J Dunia Kedokt. 2008

5. Dinas Kesehatan Provinsi Jawa Tengah. Profil Kesehatan Jawa Tengah Tahun 2016. Semarang: Dinas Kesehatan Provinsi Jawa Tengah; 2016.

6. Dinas Kesehatan Kabupaten Sukoharjo. Laporan Cakupan Pelayanan IVA. Sukoharjo: Dinas Kesehatan Kabupaten Sukoharjo; 2016.

7. Oktaviana M. Hubungan Antara Persepsi Kerentanan Individu, Keseriusan Penyakit, Manfaat Dan Hambatan Dengan Penggunaan Skrining Inspeksi Visual Asam Asetat Pada Wanita Usia Subur [Internet]. Tesis. UNS; 2015. Available from: digilib.uns.ac.id

8. Sallis JF, Owen N, Fisher EB. Ecological models of health behavior [Internet]. Health Behavior and Health Education: Theory, Research, and Practice. 2008. 465-485 p. Available from:

http://riskybusiness.web.unc.edu/files/2 015/01/Health-Behavior-and-HealthEducation.pdf\#page $=503$

9. Wahyu P. Analisis Jalur Dengan Health Belief Model Tentang Penggunaan Skrining Inspeksi Visual Asam Asetat Untuk Deteksi Dini
Kanker Serviks Pada Wanita Usia Subur di Kota Kediri. UNS; 2016.

10. Creswell, J.Q. Research Design Pendekatan Kualitatif, Kuantitatif, dan Mixed. Yogyakarta: Pustaka Pelajar; 2016.

11. Glanz, K. Barbara, K. \& Viswanath. Health Behavior and Health Education Theory, Research, and Practice. US: Jossey-Bass; 2008.

12. Dewi, N.M., Nunuk. S. \& PM. Hubungan Tingkat Pengetahuan dan Sikap Wanita Usia Subur (WUS) dengan Pemeriksaan Inspeksi Visual Asam Asetat (IVA) di Puskesmas Uleleng I. Junal Magister Kedokt Kel. 2013;1(1):57-66.

13. Ni Ketut Alit Armini, Kurnia ID, Hikmah FL. Faktor Personal, Self Efficacy dan Upaya Pencegahan Kanker Serviks Pada Perempuan Usia Produktif. J Ners. 2016;11(2):294-9. 